\title{
Turning the page
}

\author{
Juleen R. Zierath ${ }^{1,2}$
}

Published online: 25 September 2015

(C) Springer-Verlag Berlin Heidelberg 2015

After 6 years learning the ropes on the editorial board, I have proudly led Diabetologia for the past 5 years as the Editor-in-Chief. It is with a sense of both sadness and satisfaction that I write this for the final issue of my term as Editor of this prestigious journal.

Over the last 5 years, Diabetologia has received more than 10,000 submissions and I have looked at each one personally. I have worked with a dedicated team of Associate Editors and, with the help of over 3,200 referees, we have selected papers of the highest quality for publication in the journal. I hope authors feel proud to have their papers published in Diabetologia - only 15\% of all submissions are accepted. I have witnessed a rise in the quantity and quality of manuscripts and our impact factor remains strong at 6.67. Scientists and clinicians working at 9,500 institutions throughout the world have free access to Diabetologia and our papers are being widely downloaded and cited. The journal is in good shape!

In my introductory editorial in 2010 I quoted Alfred Nobel: 'If I have a thousand ideas and only one turns out to be good, I am satisfied.' Thankfully, I have found more than one good idea and, with the support of my team, have achieved a great deal.

Juleen R. Zierath

Juleen.Zierath@ki.se

1 Department of Molecular Medicine and Surgery, Karolinska Institutet, Von Eulers Väg 4a, 4 Tr., 17177 Stockholm, Sweden

2 Department of Physiology and Pharmacology, Karolinska Institutet, Stockholm, Sweden

\section{Rules and reason}

A primary achievement of my tenure has been to toughen the journal's policies and processes regarding ethics and accountability. This has included establishing a Scientific Integrity Panel, which independently and rigorously investigates claims of potential misconduct following guidelines set out by the Committee on Publication Ethics (COPE; http:// publicationethics.org/). Our expectations in terms of what is and is not acceptable behaviour on the part of authors are now set out clearly in our misconduct policy, available on the Diabetologia website (www.diabetologia-journal.org/ instructionstoauthors.html\#misconduct). We do not shy away from our responsibility to protect the integrity of the scientific record and have issued retractions and errata when these are warranted. Members of our editorial board are asked to declare any potential conflicts of interest and our reviewers are asked to follow COPE's ethical guidelines for peer-reviewers. In addition, every paper published now carries a statement that outlines the contribution of each author and identifies a guarantor, in line with recommendations of the International Committee of Medical Journal Editors (www.icmje.org).

Other safeguards put into place during my tenure to ensure the integrity of our articles include screening all potentially publishable papers to detect untoward text recycling and manipulation of images. All manuscripts submitted to Diabetologia are scanned for possible duplicate or prior publication using the iThenticate plagiarism detection system (www.ithenticate.com/). Image editing software and investigative techniques are now used to screen images in accepted papers to identify any manipulation. Any inappropriate manipulation is investigated by the Scientific Integrity Panel in the first instance, following guidelines set out by COPE. The author Philip Pullman said: 'It's only through honesty and courage that science can work at all.' 
[1]. Although the screening results in extra work on the part of authors and editors, not to mention the editorial staff, we can all surely agree that fair practice benefits us all.

In conjunction with a number of other journals and societies, we also published a Statement of Principle in November 2014, reaffirming our mission to report and disseminate data from scientific investigation, evolving medical care and innovative treatments, and noting that the journal will refrain from publishing articles addressing political issues that fall outside either research funding or healthcare delivery.

\section{The authors' experience}

In an attempt to ensure accurate and thorough reporting, we ask authors to provide CONSORT, STROBE, MOOSE or PRISMA checklists, where relevant, at submission. Also, in response to the ever-increasing length of figure legends, we now include these in the word limit for articles. As a result, manuscripts have become more considered and succinct.

Authors can expect to receive feedback on their peerreviewed manuscript in 4 weeks, and the time from acceptance to online publication is, on average, 30 days. Authors of a paper unsuitable for Diabetologia, for whatever reason, will receive a triage decision within a few days. Although this may grate initially, this gives authors the opportunity to send their paper elsewhere without unnecessary delay.

Even though fewer than 100 paper copies of the journal are printed each month, we still strive to create a very attractive cover highlighting one of the articles in the issue. Although photo libraries offer an array of interesting images, it is even better when authors get involved and supply their own pictures perfectly illustrating their research. We archive journal cover images on our website (www.diabetologia-journal.org/ picturegallery.html). There is enormous pride in having a paper published in our journal-being the 'cover story' as well is the cherry on top of the cake!

\section{Projects}

It has been a privilege to work with various field leaders on some original projects.

In 2012 we published a year-long series of editorials entitled 'Then and Now'. These pieces looked back on Diabetologia's classic papers, describing their major findings and assessing their impact on the field today. The series covered a diverse range of topics, from exercise and diet to descriptive epidemiology. My hope was to explain how what we knew then has contributed to what we know now.

In contrast, to celebrate Diabetologia's 50th anniversary earlier this year, we published a series of innovative commentaries entitled ' 50 Years Forward'. Its aim was to look into the future of the field and hypothesise and conceptualise without restraints about what might be to come.

\section{Reviews}

First-class reviews are important to any journal and our reviews editors have worked hard to solicit the best reviews on a wide range of topics, from basic molecular mechanisms to the most recent epidemiology data, that collectively underscore the latest research in disease mechanisms, pathophysiology and clinical care. As a result, the number of invited reviews published has increased from only one in 2011 to one a month in 2015.

\section{Highlighting our research}

I am proud of the measures I have implemented during my editorship to increase the visibility of Diabetologia and highlight outstanding papers. Every month I select five articles that the Associate Editors and I deem to be of exceptional interest. In order to increase readership and downloads, the authors are invited to write a synopsis and these are given prime position at the front of the issue and on our website. In addition, the full text of these 'Up front' articles is made freely available.

We appointed a press officer in 2012 and work with authors to issue press releases on the journal's most engaging papers. As a result we have had coverage in major print, broadcast and online media all over the world - great publicity for authors, the journal and the EASD.

Finally, we have recently embraced social media and through our Twitter account @DiabetologiaJnl have connected with researchers in the field, circulated news and highlighted papers. We hope to see you on Twitter soon!

\section{Sally forth}

Of course there will forever be opportunities and a need to develop the journal and I am delighted to be able to hand the baton to Professor Sally Marshall at Newcastle University. Having already been Editor-in-Chief of Diabetic Medicine, Sally is familiar with the pressures and pleasures of running a journal. Sally has also served as an Associate Editor of Diabetologia for the past 5 years. As a sensible and decisive clinical researcher who is rich in wisdom and wit, Sally's editorship is sure to be excellent. 


\section{Thank you}

From the journal's beginnings it has been produced by international publisher Springer. In recent years the relationship between Diabetologia and Springer has grown ever stronger and we appreciate the continued support and advice of staff there.

Throughout my time as Editor-in-Chief I have been surrounded by an exceptional team of Associate Editors and members of the Advisory Board from all over the world. Every week Associate Editors are given at least one new manuscript to handle - often more during busy periods. Quite often they are asked for advice on further papers and some even find time to review other manuscripts on top. Without their guidance, their expertise and their willingness to give up their free time, Diabetologia would not be the journal it is.

In creating the charity European Diabetology, the EASD has bolstered Diabetologia's future and secured the editorial office a permanent home in Bristol, UK. In 2014, the staff moved from their temporary office into a new building on the Southmead Hospital site and are now happily nestled alongside colleagues and kindred spirits from the University of Bristol's School of Clinical Sciences. Their kitchen cupboard has quite possibly the most eclectic range of leaf teas and, inspired by research published in our own journal, the office has a well-used, electronic standing desk.

To the Editorial Office staff I am grateful for their daily commitment and personal touches. Unlike some other publications, emails are not automated but are personalised to suit the recipient, adding a convivial and congenial voice to our already respected journal. The positive feedback received by the office is savoured and shows that authors, referees and editors appreciate this personal touch. Rare criticisms are also saved so that the machine can be oiled and even more finely tuned.

In my new role as President of the EASD, we will all still be working together to further knowledge of, education about and research into diabetes across Europe and beyond, so this is not adieu but au revoir. I look forward to seeing Diabetologia continue to go from strength to strength.

\section{Reference}

1. Pullman P (2015) The origin of the universe. Available from www. philip-pullman.com/assets_cm/files/pdf/the_origin_of_the universe.pdf, accessed 7 May 2015 